Research article Open Access

\title{
Circulating immune complexes contain citrullinated fibrinogen in rheumatoid arthritis
}

\author{
Xiaoyan Zhao ${ }^{1,2}$, Nwora Lance Okeke1,2, Orr Sharpe ${ }^{1,2}$, Franak M Batliwalla ${ }^{3}$, Annette T Lee ${ }^{3}$, \\ Peggy P Ho${ }^{4}$, Beren H Tomooka ${ }^{1,2}$, Peter K Gregersen ${ }^{3}$ and William H Robinson ${ }^{1,2}$
}

${ }_{1}$ GRECC, VA Palo Alto Health Care System, 3801 Miranda Avenue, Palo Alto, CA 94304, USA

2Department of Medicine, Division of Immunology and Rheumatology, Stanford University School of Medicine, 269 Campus Drive West, Stanford, CA 94305, USA

${ }^{3}$ Robert S. Boas Center for Genomics and Human Genetics, Feinstein Institute for Medical Research, 350 Community Drive, Manhasset, NY 11030 , USA

${ }^{4}$ Department of Neurology and Neurological Sciences, Stanford University School of Medicine, 269 Campus Drive West, Stanford, CA 94305, USA

Corresponding author: William H Robinson, wrobins@stanford.edu

Received: 10 Jun 2008 Revisions requested: 1 Jul 2008 Revisions received: 22 Jul 2008 Accepted: 18 Aug 2008 Published: 18 Aug 2008

Arthritis Research \& Therapy 2008, 10:R94 (doi:10.1186/ar2478)

This article is online at: http://arthritis-research.com/content/10/4/R94

(c) 2008 Zhao et al.; licensee BioMed Central Ltd.

This is an open access article distributed under the terms of the Creative Commons Attribution License (http://creativecommons.org/licenses/by/2.0), which permits unrestricted use, distribution, and reproduction in any medium, provided the original work is properly cited.

\begin{abstract}
Introduction There is increasing evidence that autoantibodies and immune complexes (ICs) contribute to synovitis in rheumatoid arthritis (RA), yet the autoantigens incorporated in ICs in RA remain incompletely characterised.

Methods We used the C1q protein to capture ICs from plasma derived from human RA and control patients. Antibodies specific for immunoglobulin were used to detect ICs, and fibrinogen antibodies were used to detect fibrinogen-containing ICs. RA and control plasma were separated by liquid chromatography, and fractions then characterised by ELISA, immunoblotting and mass spectrometry. Immunohistochemical staining was performed on rheumatoid synovial tissue.
\end{abstract}

Results C1q-immunoassays demonstrated increased levels of $\lg G(p=0.01)$ and $\operatorname{lgM}(p=0.0002)$ ICs in plasma derived from RA patients possessing anti-cyclic citrullinated peptide (CCP+) autoantibodies as compared with healthy controls. About onehalf of the anti-CCP+ RA possessed circulating ICs containing fibrinogen $(p=0.0004)$. Fractionation of whole RA plasma revealed citrullinated fibrinogen in the high molecular weight fractions that contained ICs. Positive correlations were observed between fibrinogen-containing ICs and anticitrullinated fibrinogen autoantibodies, anti-CCP antibody, rheumatoid factor and certain clinical characteristics. Immunohistochemical staining demonstrated co-localisation of fibrinogen, immunoglobulin and complement component $\mathrm{C} 3$ in RA pannus tissue. Mass spectrometry analysis of immune complexes immunoprecipitated from RA pannus tissue lysates demonstrated the presence of citrullinated fibrinogen.

Conclusion Circulating ICs containing citrullinated fibrinogen are present in one-half of anti-CCP+ RA patients, and these ICs co-localise with $\mathrm{C} 3$ in the rheumatoid synovium suggesting that they contribute to synovitis in a subset of RA patients.

\section{Introduction}

Rheumatoid arthritis (RA) is a chronic autoimmune synovitis affecting $0.6 \%$ of the world's population [1], yet the mechanisms underlying the initiation and progression of RA are still not completely understood. The presence of immune complexes (ICs) in the blood and synovial fluid of patients with RA is well described $[2,3]$, and there is evidence they are involved in the activation of the complement cascade in RA synovial tis-

$\mathrm{BSA}=$ bovine serum albumin; CCP = cyclic-citrullinated peptides; FPLC = fast protein liquid chromatography; GPI = glucose-6-phosphate isomerase; $\mathrm{HLA}=$ human leucocyte antigen; $\mathrm{HRP}=$ horseradish peroxidase; IBD = inflammatory bowel disease; IC = immune complex; JRA = juvenile rheumatoid arthritis; MHC = major histocompatibility complex; PBS = phosphate buffered saline; PBST = phosphate buffered saline with $0.05 \%$ Tween$20 ; \mathrm{PS}=$ psoriasis; PsA = psoriatic arthritis; RA = rheumatoid arthritis; RF = rheumatoid factor; SLE = systemic lupus erythematosus. 
sue [4]. However, apart from rheumatoid factor (RF) [5] and anti-collagen type II [6], the identity of the antigens involved in ICs in RA remains obscure.

Studies suggest critical roles for protein citrullination, B cells and autoantibodies in the pathogenesis of RA [7-10]. Citrullination is the post-translational conversion of arginine to citrulline, and in RA autoantibodies targeting cyclic citrullinated peptide (CCP) provides a sensitivity of approximately $70 \%$ and a specificity of $97 \%$ for the diagnosis of RA $[7,11,12]$. The citrullinated $\alpha$ - and $\beta$-chains of fibrin have been identified as potential targets of the autoantibody response in RA [13] and citrullinated fibrinogen is detected in RA synovial fluid [14].

Korganow and colleagues identified ICs involving glucose-6phosphate isomerase (GPI) as mediating joint inflammation in their spontaneous K/BxN model [15]. These mice produce anti-GPI antibodies that form ICs that are deposited on articular surfaces and activate the alternative complement pathway to cause synovitis. Although studies suggest that GPI is not a specific autoantigen in RA [16], it is possible that the mechanisms involved in anti-GPI antibody arthritis and IC arthritis are relevant to a subset of human RA patients.

RA is characterised by excessive generation and breakdown of fibrinogen [17]. The citrullinated $\alpha$ - and $\beta$-chains of fibrin have also been identified as a potential target of the autoantibody response in RA $[13,18]$ and citrullinated fibrinogen has been identified in synovial fluid derived from RA patients [14]. Autoantibodies against citrullinated fibrinogen have been described to provide diagnostic value in arthritis $[18,19]$. We previously generated synovial microarrays containing more than 500 proteins and peptides representing candidate autoantigens in RA, including protein and overlapping peptides representing native and citrullinated fibrinogen. Synovial microarray analysis demonstrated targeting of citrullinated fibrinogen in RA [20].

The methods described for the detection of ICs include chemical precipitation methods from as far back as the 1960s [21] and biological methods such as precipitation with Clq [22]. We adapted $\mathrm{C} 1 \mathrm{q}$ capture immunoassays to utilise fibrinogenspecific secondary antibodies to identify fibrinogen-containing ICs, and applied these immunoassays to plasma samples derived from RA and control patients.

In the present study, we further investigated the targets of the autoantibody response and the antigens incorporated in ICs in RA. We demonstrated that one-half of anti-CCP+RA patients possessed circulating (blood) ICs containing citrullinated fibrinogen, and that fibrinogen, immunoglobulin and complement component $\mathrm{C} 3$ co-localize in pannus tissue derived from RA patients. These data suggest that autoantibody targeting of citrullinated fibrinogen results in the formation of fibrinogen- containing ICs that characterise a subset of anti-CCP+ RA patients and may contribute to synovitis in RA.

\section{Materials and methods Human samples}

All RA and control plasma and joint samples were obtained and studied with informed consent under Institutional Review Board approved protocols. The plasma samples used came from the Multiple Autoimmune Disease Genetics Consortium [23] and the Stanford Arthritis Center, collected in EDTA tubes (Table 1). The diagnosis of RA was made based on the American College of Rheumatology 1987 criteria [24].

\section{Mass spectrometry analysis}

For in-gel digestion, protein spots were excised from the gel and treated with trypsin overnight at $37^{\circ} \mathrm{C}$. The tryptic peptides were resolved by high-performance liquid chromatography (HPLC) using a Zorbax 300SB-C18 nanocolumn (Agilent Technologies, Palo Alto, CA, USA) packed with $3.5 \mu \mathrm{m}$ particles (Agilent Technologies, Palo Alto, CA, USA) and eluted at $300 \mathrm{~nL} /$ minute with a 60 minute linear gradient from 0 to $95 \%$ acetonitrile containing $0.1 \%$ formic acid. Separated peptides were electrosprayed into an ion trap mass spectrometer (XCT Plus, Agilent Technologies, Palo Alto, CA, USA). For ICs immunoprecipitated from RA pannus tissue lysates, the precipitated complexes were directly digested with trypsin before mass spectrometry analysis. Proteins were identified based on raw MS/MS data compared with a SwissProt database using Mascot (Matrix Science, UK) with valid peptide hits.

\section{Detection of anti-citrullinated fibrinogen autoantibodies} Native fibrinogen (Calbiochem, San Diego, CA, USA) was citrullinated in vitro with a peptidylarginine deiminase derived from rabbit skeletal muscle (Sigma, St. Louis, MO, USA) using protocols previously described [25]. Anti-citrullinated fibrinogen autoantibodies were assayed as previously described $[13,26,27]$. Briefly, native fibrinogen or citrullinated fibrinogen was coated on ELISA plates (MaxiSorp; Nunc, Rochester, NY, USA) overnight at $4^{\circ} \mathrm{C}$ at a concentration of $20 \mu \mathrm{g} / \mathrm{mL}$. Subsequent incubations and washes were performed at room temperature. The plates were blocked with $3 \%$ bovine serum albumin (BSA) in phosphate buffered saline with $0.05 \%$ Tween-20 (PBST) (Sigma, St. Louis, MO, USA) for one hour, washed and incubated with centrifuged plasma (diluted 50fold) on a shaker for 1.5 hours. Anti-fibrinogen autoantibody was detected using horseradish peroxidase (HRP)-conjugated secondary reagents specific for human IgG ( $\gamma$ chain) or IgM ( $\mu$ chain) specific antibodies diluted to 1:20,000.

\section{Quantitation of immune complexes}

ELISA plates were coated with $20 \mu \mathrm{g} / \mathrm{mL}$ C1q (Sigma, St. Louis, MO, USA) in phosphate buffered saline (PBS) overnight at $4^{\circ} \mathrm{C}$. Subsequent incubations and washes were performed at room temperature. The plates were blocked with 3\% BSA in PBST for one hour. After washing, plasma from RA 
Table 1

\begin{tabular}{|c|c|c|c|c|c|c|}
\hline Sample source & Disease & Number & Female, no. (\%) & Age (range) & anti-CCP positive, no. (\%) & RF positive, no. (\%) \\
\hline \multirow[t]{2}{*}{ Dr. P. Gregersen, plasma set 1} & RA & 30 & $28(93)$ & 72.6 (51 to 89$)$ & $20(67)$ & $24(80)$ \\
\hline & Healthy & 10 & & & & \\
\hline \multirow[t]{6}{*}{ Dr. P. Gregersen, plasma set 2} & IBD & 20 & $13(65)$ & 46.4 (23 to 82 ) & & \\
\hline & JRA & 20 & $16(80)$ & 37.3 (10 to 71$)$ & $6(30)$ & $6(30)$ \\
\hline & PsA & 14 & $11(79)$ & 52.6 (23 to 75$)$ & & \\
\hline & PS & 20 & $10(50)$ & $55.3(22$ to 86$)$ & & \\
\hline & RA & 20 & 19(95) & $59.0(35$ to 89$)$ & & \\
\hline & SLE & 20 & $13(65)$ & 51.3 (29 to 67 ) & & \\
\hline
\end{tabular}

CCP, cyclic-citrullinated peptides; RF, rheumatoid factor; RA, rheumatoid arthritis; IBD, inflammatory bowel disease; JRA, juvenile rheumatoid arthritis; PsA, psoriatic arthritis; PS, psoriasis; SLE, systemic lupus erythematosus.

patients or healthy controls were diluted to 1:50 in PBST and incubated on a shaker for 1.5 hours. ICs were detected with HRP-conjugated rabbit antiserum specific for human IgG or IgM (Jackson Immunoresearch, West Grove, PA, USA).

\section{Quantitation of fibrinogen-containing immune complexes}

ELISA plates coated with C1q were blocked with $3 \%$ BSA in PBST for one hour. After washing, plasma from RA patients or healthy controls was diluted to $1: 10$ and incubated on a shaker for 1.5 hours. Fibrinogen contained within the captured ICs was detected using a 1:4000 dilution of HRP-conjugated rabbit anti-human fibrinogen antiserum (Dako, Carpinteria, CA, USA).

\section{Anti-CCP and RF (IgM) ELISA}

The anti-CCP (Euro Diagnostica, Malmö, Sweden) and RF ELISA kits (Alpha Diagnostic International, San Antonio, TX, USA) were used according to the manufacturers' protocol, except that plasma was used instead of serum. Anti-CCP and $\mathrm{RF}$ values of the samples were expressed as $\mathrm{IU} / \mathrm{mL}$.

\section{Fractionation of plasma samples}

The plasma samples were filtered by a $0.45 \mu \mathrm{m}$ cellulose acetate membrane in a Spin-x centrifuge tube filter (Corning, Corning, NY, USA) to remove cell debris and precipitates. A volume of $150 \mu \mathrm{L}$ of the filtered plasma sample was injected into a fast protein liquid chromatography (FPLC) system (GE Healthcare Bio-Sciences, Piscataway, NJ, USA) equipped with a Superdex 200 10/300 gel filtration column (Amersham Biosciences, Piscataway, NJ, USA). A mixture of protein standard containing human fibrinogen, human albumin and lgG was run in parallel to further identify different peaks. All liquid chromatography runs were programmed at a flow rate of $0.4 \mathrm{~mL} /$ minute with PBS and fractions of $0.5 \mathrm{~mL}$ were collected. To measure total protein content of the fractions, $20 \mu \mathrm{L}$ of each fraction was mixed with $100 \mu \mathrm{L}$ of BCA buffer (Pierce
Biotechnology, Rockford, IL, USA) and the mixture was incubated at $37^{\circ} \mathrm{C}$ for 30 minutes before the results were read at $562 \mathrm{~nm}$ on a spectraMAX190 instrument (Molecular Devices, Sunnyvale, CA, USA). To measure $\lg G$ and fibrinogen ICs, 50 $\mu \mathrm{L}$ of each fraction was applied to the C1q ELISA described above. To measure total IgG and fibrinogen content, the fractions were first diluted 10-fold with PBS. Then $1 \mu \mathrm{L}$ of the dilutes was deposited onto a nitrocellulose membrane and left to dry overnight. After blocking with 5\% milk in PBST, HRPconjugated anti-human IgG or anti-human fibrinogen was applied to the membranes. Detection was carried out with SuperSignal West Pico Substrate (Pierce Biotechnology, Rockford, IL, USA). The densitometry of exposed film were measured with FluorChem imaging system (Alpha Innotech, San Leandro, CA, USA).

\section{Immunoblot}

Plasma fractions were further separated with Precast Criterion Tris- $\mathrm{HCl}$ gels (4 to 20\% linear gradient; Bio-Rad, Hercules, CA, USA), and separated proteins blotted onto nitrocellulose membranes. After blocking with $3 \%$ BSA in PBS, sera from RA patients or healthy controls were used to probe the membranes. Bound antibodies were detected with HRP-conjugated anti-human lgG (Jackson Immunoresearch, West Grove, PA, USA) using a SuperSignal kit (Pierce biotechnology, Rockford, IL, USA) and chemiluminescence was imaged with FluorChem imaging system (Alpha Innotech, San Leandro, CA, USA). Immunoblot with anti-modified citrulline was performed with an anti-citrulline detection kit (Upstate, Chicago, IL, USA) according to the manufacturer's instructions $[13,27]$.

\section{Immunohistochemistry}

Slides were deparaffinised and hydrated with water. Endogenous peroxidase was inhibited with 3\% hydrogen peroxide, and non-specific staining blocked with DAKO Protein Block Serum-Free (Dako, Carpinteria, CA, USA). Staining for com- 
plement C3 was performed using a 1:2000 dilution of rabbit polyclonal antibodies against human complement C3 (Dako, Carpinteria, CA, USA). For fibrinogen and IgG staining, pretreatment of proteinase K (Dako, Carpinteria, CA, USA) was used before the primary antibody incubation. Slides positive for fibrinogen were immunohistochemically stained with a rabbit polyclonal antibody against human fibrinogen (Dako, Carpinteria, CA, USA), at room temperature at a dilution of $1: 1600$ for 30 minutes. After incubation with primary antibody, the tissue sections were sequentially incubated with Dako Envision+ Rabbit System Labeled Polymer HRP (Dako, Carpinteria, CA, USA) or biotinylated rabbit anti-goat antibodies (Vector, Burlingame, CA, USA) followed by streptavidin HRP (Dako, Carpinteria, CA, USA). Staining was developed with Liquid DAB+ (Dako, Carpinteria, CA, USA) and counterstained with haematoxylin and eosin.

\section{Statistics}

All statistics were run using InStat ${ }^{\mathrm{TM}}$ software (GraphPad Software Inc., San Diego, CA, USA). For quantitation of ICs and autoantibodies to fibrinogen, unpaired $t$-tests with Welch correction were used.

\section{Results \\ Identification of fibrinogen-containing circulating immunecomplexes in RA}

$\mathrm{C} 1 \mathrm{q}$ binds aggregated immunoglobulin $\mathrm{Fc}$ regions and has been used to capture and quantitate ICs [28]. We used C1qcapture immunoassays and HRP-labelled secondary antibodies specific for human $\lg G$ and $\lg M$ to quantitate circulating ICs in plasma derived from anti-CCP+ RA, anti-CCP- RA and healthy control patients (Figures 1a,b). Elevated circulating $\lg G(p=0.01$; Figure $1 a)$ and $\lg M(p=0.0002$; Figure $1 b)$ ICs were observed in anti-CCP+ RA patients when compared with healthy controls. Most anti-CCP- RA patients did not possess circulating ICs (Figures 1a,b).

To determine if circulating ICs containing fibrinogen are present in RA, a fibrinogen-specific secondary antibody was used after $\mathrm{C} 1 \mathrm{q}$ capture. One-half of anti-CCP+ RA patients possessed fibrinogen-containing ICs when compared with healthy controls $(p=0.0004)$ and anti-CCP-RA patients $(p=$ 0.0008) (Figure 1c). Anti-CCP+ RA patients showed elevated titres of fibrinogen-containing ICs relative to anti-CCP- RA and healthy controls with low standard deviations (Figure 1e).

To further demonstrate that the observed fibrinogen-containing ICs did not result from non-specific binding of fibrinogen to immobilised $\mathrm{C} 1 \mathrm{q}$, we immobilised anti-C1q monoclonal antibodies to capture the C1q-bound ICs followed by detection with anti-fibrinogen antibodies. Similar results were obtained with anti-C1q monoclonal antibody capture as compared with $\mathrm{C} 1 \mathrm{q}$ capture of ICs, and yielded a $\mathrm{R}^{2}$ value of 0.9 in a linear regression analysis of the two assays (data not shown). Fibrinogen-containing ICs were also analysed from freshly collected plasma samples from both anti-CCP+ RA and anti-CCP- RA patients (within two hours of blood draw using EDTA plasma collection tubes). Compared with the same samples after a freeze-thaw cycle, no difference was detected (Figure 1f).

To demonstrate that fibrinogen-containing ICs were specifically detected in RA compared with other autoimmune diseases, these ICs were analysed from plasma samples collected in a panel of healthy $(n=10)$, inflammatory bowel disease $(n=20)$, juvenile RA $(n=20)$, psoriatic arthritis ([PsA] $n=14)$, psoriasis $(n=20)$, systemic lupus erythematosus ( $n$ $=20)$, and RA ( $n=20)$ patients (Figure 1d). A subset of RA and a small subset of juvenile RA patients exhibited elevated circulating ICs containing fibrinogen, while patients with other autoimmune diseases did not (Figure 1d). The subset of juvenile RA patients possessing circulating ICs containing fibrinogen also possessed anti-citrullinated fibrinogen antibodies, RF and anti-CCP antibodies (Table 2). Chart reviews performed on this subset of juvenile RA patients revealed that they exhibited symmetrical polyarthritis (Table 2). These observations suggest that this subset of 'juvenile RA' patients in fact have adult RA, and is consistent with prior reports of $13 \%$ of juvenile RA patients exhibiting anti-CCP antibodies and clinical features consistent with adult RA [29].

\section{Liquid chromatographic separation demonstrates co- fractionation of citrullinated fibrinogen with immune complexes}

To demonstrate that the fibrinogen-containing ICs in plasma are physically distinct from free fibrinogen and free immunoglobulin, we used size exclusion chromatography as previously described [16]. Size exclusion chromatography was applied to fractionate plasma derived from an RA patient with fibrinogen-containing circulating ICs, an RA patient with circulating ICs but not fibrinogen-containing circulating ICs, a PsA patient and a healthy control (Figure 2a). Forty-five fractions were generated of each patient's plasma and each fraction was assayed for ICs, fibrinogen-containing ICs, total immunoglobulin, total fibrinogen and total protein.

ELISA analysis of the fractions containing IgG ICs showed two peaks in the elution profile of both RA samples, but not in the corresponding fractions from the PsA and healthy control samples (Figure 2a, green line). The first peak (RA1 and RA2, green line) corresponded to the first three fractions after the void volume, which had a molecular mass of $300 \mathrm{kD}$ or higher, and corresponded to the fractions in which ICs eluted. The second peak (RA1 and RA2, green line) corresponded to free $\lg G$ as compared with a chromatography run of standards (STD, blue line). ELISA analysis of fibrinogen ICs on RA1 (which possessed fibrinogen ICs) showed a single peak (Figure $2 \mathrm{a}, \mathrm{RA} 1$, red line) that was eluted in the same fractions at the IgG IC peak (Figure 2a, RA1 and RA2, first peak of green 
(a)

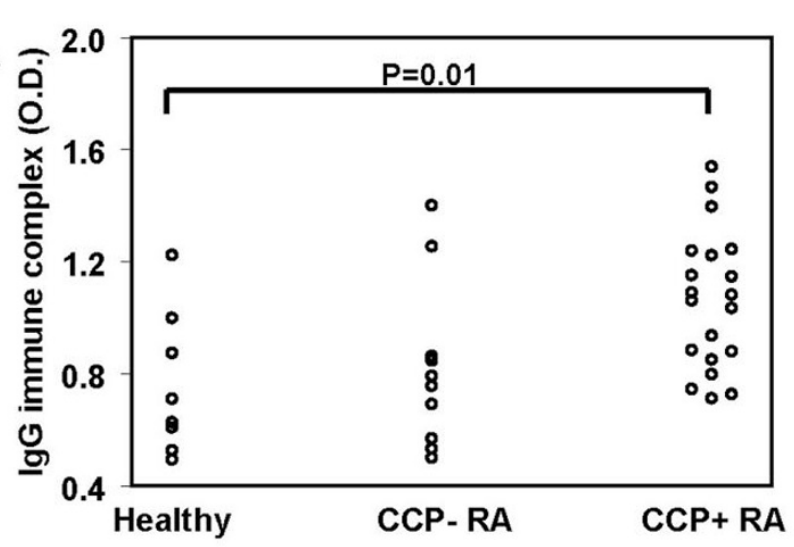

(c)

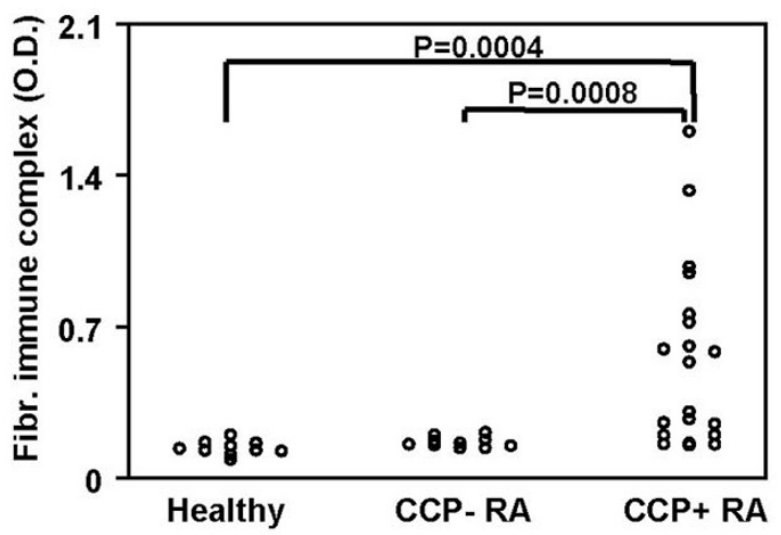

(e)

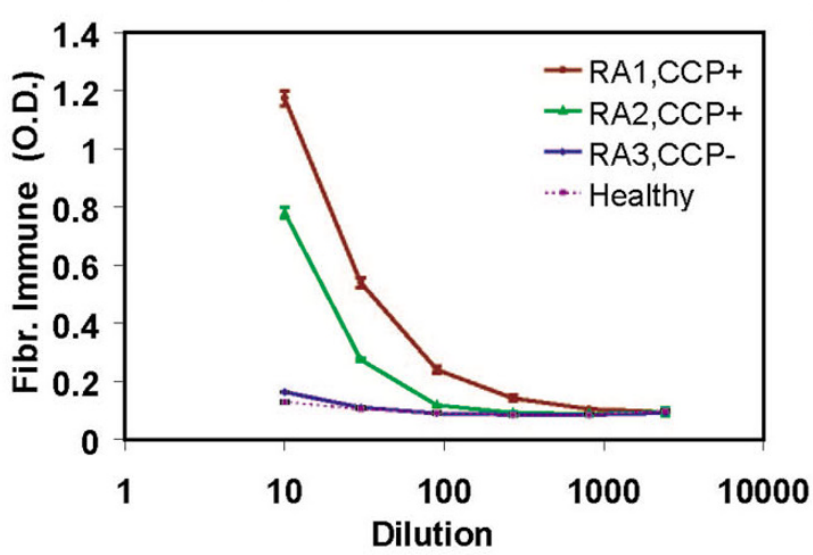

(b)

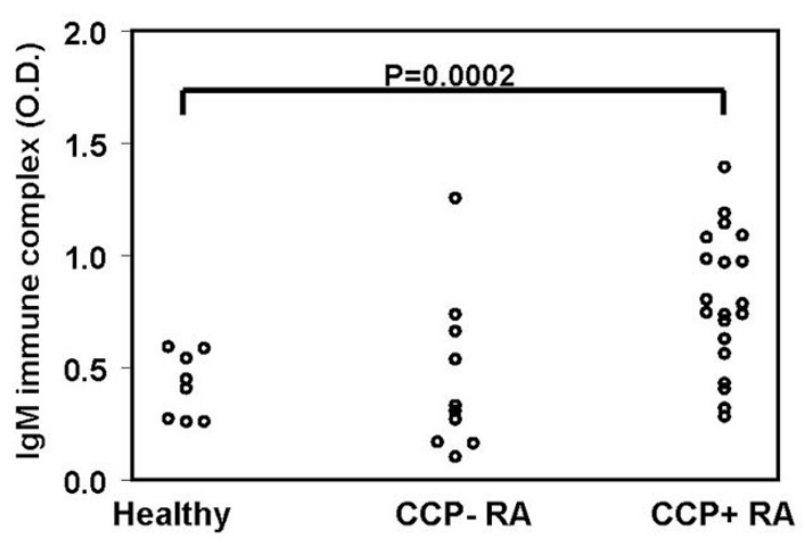

(d)

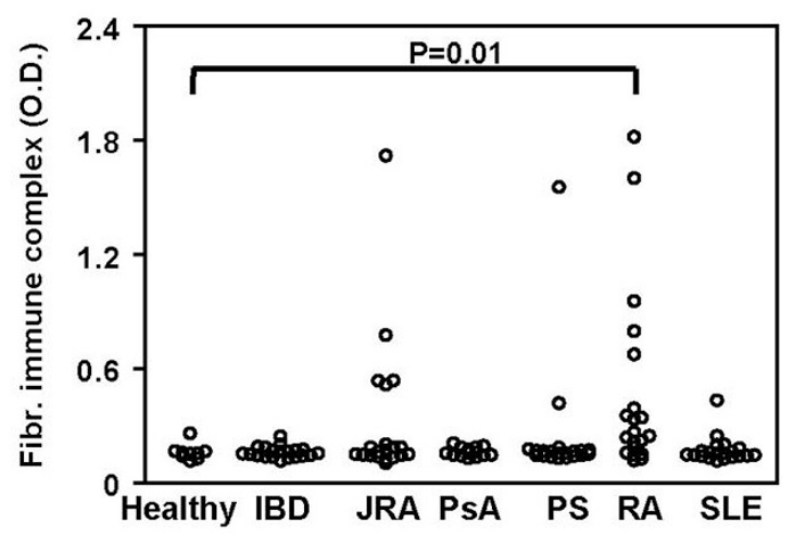

(f)

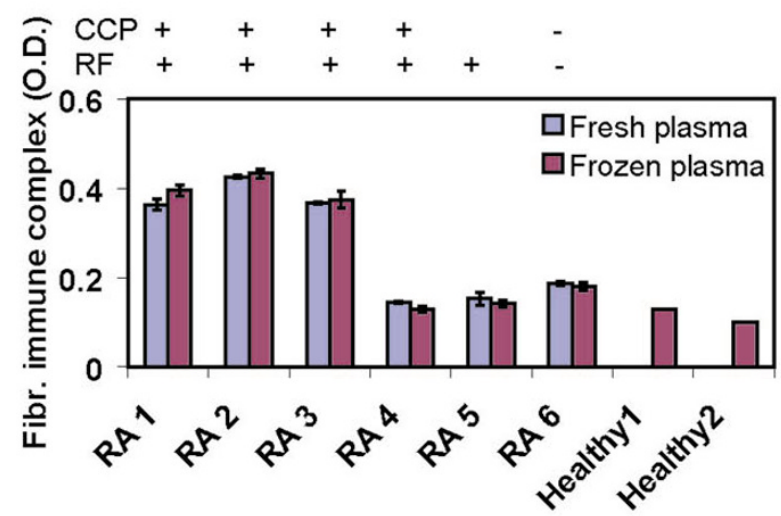

Fibrinogen-containing circulating immune complexes (ICs) in rheumatoid arthritis (RA). Circulating (a) IgG and (b) IgM ICs were detected in plasma derived from healthy individuals and anti-cyclic-citrullinated peptides (CCP) - and anti-CCP+ RA patients. ELISA plates were coated with C1q, incubated with 1:50 dilutions of plasma samples and horseradish peroxidase (HRP)-conjugated (a) anti-lgG or (b) anti-lgM secondary antibodies were used to detect the immunoglobulin isotypes contained in ICs. (c, d) Circulating fibrinogen-containing ICs were detected using HRP-conjugated fibrinogen-specific antisera as the secondary reagent. Statistical comparisons are based on an unpaired $t$-test with Welch correction. (e) Fibrinogencontaining ICs were detected with different dilutions of RA patient samples and healthy controls. Error bars represent the standard deviation of results from triplicate wells. (f) Fibrinogen-containing ICs were detected in fresh plasma and freeze-thawed plasma samples with no significant differences in values (data for anti-CCP status of RA5 is not available). 
Table 2

Clinical and laboratory characteristics of the juvenile rheumatoid arthritis (JRA) patients characterised

\begin{tabular}{|c|c|c|c|c|c|c|c|}
\hline Sample & $\begin{array}{l}\text { Clinical features and } \\
\text { rheumatoid factor status }\end{array}$ & $\begin{array}{l}\text { Age } \\
\text { Onset }\end{array}$ & $\begin{array}{l}\text { Age } \\
\text { History }\end{array}$ & Fibrinogen ICs (O.D.) & Anti-cit. fibrinogen IgG (O.D.) & $\begin{array}{c}\text { anti-CCPa } \\
(\mathrm{IU} / \mathrm{mL})\end{array}$ & $\begin{array}{c}\mathrm{RF}^{\mathrm{b}} \\
(\mathrm{IU} / \mathrm{mL})\end{array}$ \\
\hline JRA 1 & Polyarthritis, RF- & 2 & 2 & 0.18 & 0.11 & 21.3 & 11.7 \\
\hline JRA 4 & Polyarthritis, RF+ & 13 & & 0.77 & 1.25 & 841.1 & 127.6 \\
\hline JRA 8 & Polyarthritis, RF+ & 3 & 16 & 0.53 & 0.43 & 483.2 & 262.6 \\
\hline JRA 13 & Polyarthritis, RF+ & 13 & 13 & 0.54 & 1.45 & 255.4 & 274.7 \\
\hline JRA 17 & Systemic arthritis & & & 0.15 & 0.10 & 24.8 & 24.9 \\
\hline JRA 22 & Polyarthritis, RF- & 15 & 15 & 0.13 & 0.09 & 22.7 & 27.1 \\
\hline JRA 27 & Polyarthritis, RF- & 1 & 2 & 0.10 & 0.08 & 20.3 & 7.6 \\
\hline JRA 31 & Persistent oligoarthritis & & & 0.16 & 0.13 & 21.5 & 7.3 \\
\hline JRA 32 & Polyarthritis, RF- & 5 & 5 & 0.12 & 0.37 & 26.7 & 6.3 \\
\hline JRA 41 & Enthesitis-related arthritis & 13 & 14 & 0.14 & 0.08 & 20.8 & 13.1 \\
\hline JRA 42 & Systemic arthritis & 12 & 12 & 0.17 & 0.08 & 21.8 & 7.1 \\
\hline JRA 44 & Polyarthritis, RF- & 9 & 9 & 0.19 & 0.09 & 20.9 & 10.1 \\
\hline JRA 49 & Polyarthritis, RF+ & 9 & & 1.72 & 0.74 & 1275.4 & 295.2 \\
\hline JRA 51 & Systemic arthritis & 5 & 5 & 0.14 & 0.09 & 21.4 & 7.6 \\
\hline JRA 71 & Polyarthritis, RF+ & & 10 & 0.19 & 0.21 & 360.9 & 186.1 \\
\hline JRA 79 & Polyarthritis, RF- & 4 & 4 & 0.20 & 0.10 & 22.1 & 11.7 \\
\hline JRA 88 & Polyarthritis, RF+ & 11 & 11 & 0.51 & 0.35 & 287.0 & 236.4 \\
\hline JRA 106 & Extended oligoarthrits & 1 & 3 & 0.15 & 0.12 & 22.0 & 10.0 \\
\hline JRA 110 & Persistent oligoarthritis & & & 0.15 & 0.10 & 24.9 & 14.6 \\
\hline JRA 112 & Enthesitis related arthritis & & & 0.14 & 0.12 & 22.5 & 15.9 \\
\hline
\end{tabular}

a,bMeasured with commercial kits. JRA, juvenile rheumatoid arthritis; IC, immune complex; CCP, cyclic-citrullinated peptides; RF, rheumatoid factor; O.D., optical density

line). Similar analysis on RA2 did not show a co-eluted peak (RA2, red line).

To further determine that fibrinogen detected from IC fractions was not a contamination from free fibrinogen in blood, free fibrinogen from each RA1 fraction was quantitated by dot assay (Figure 2a, right panel, pink line). The peak of free fibrinogen was well separated from the peak of fibrinogen IC (Figure $2 \mathrm{a}$, right panel, red line), as shown by the first two dotted lines. PsA and healthy control patients did not possess circulating ICs (PsA and healthy, green line). It is possible that following the collection of the plasma fractions, that the free $\lg G$ fractions that contained high levels of $\lg G$ developed some $\lg G$ aggregates that were then detected by the $\lg G I C$ assay. These results demonstrate that the fibrinogen-containing circulating ICs observed co-elute with the IgG ICs, and that the fractions containing fibrinogen-ICs are distinct from those containing free fibrinogen and free immunoglobulin.

To determine if the fibrinogen present in circulating ICs is citrullinated, the FPLC fractions that contained fibrinogen ICs were separated by sodium dodecyl sulfate polyacrylamide gel electrophoresis (SDS-PAGE) and immunoblotted with antimodified citrulline antibody (Figure $2 b$ ). Citrullinated polypeptides that co-migrated with fibrinogen polypeptides were detected only in the fractions derived from RA patients but not in the corresponding fractions isolated from controls. The band, indicated as fibrinogen beta chain, was further analysed by mass spectrometry. Two distinct citrullinated peptides from the fibrinogen beta chain were identified (Figure 2c).

\section{Laboratory and clinical features associated with fibrinogen-containing circulating immune complexes}

We observed positive correlations between fibrinogen-containing ICs with IgG and IgM ICs, anti-citrullinated fibrinogen antibodies, anti-CCP antibodies, RF and certain clinical characteristics (Figures $3 a-h$ ). Of anti-CCP+ RA patients, threequarters possess anti-citrullinated fibrinogen antibodies (Figures $3 c, i)$ and one-half possess fibrinogen-containing circulating ICs (Figures 3d, i). All patients with fibrinogen-containing circulating ICs possess RF, while more than one-half of RF+ patients did not possess fibrinogen-containing ICs (Figures 
(a)
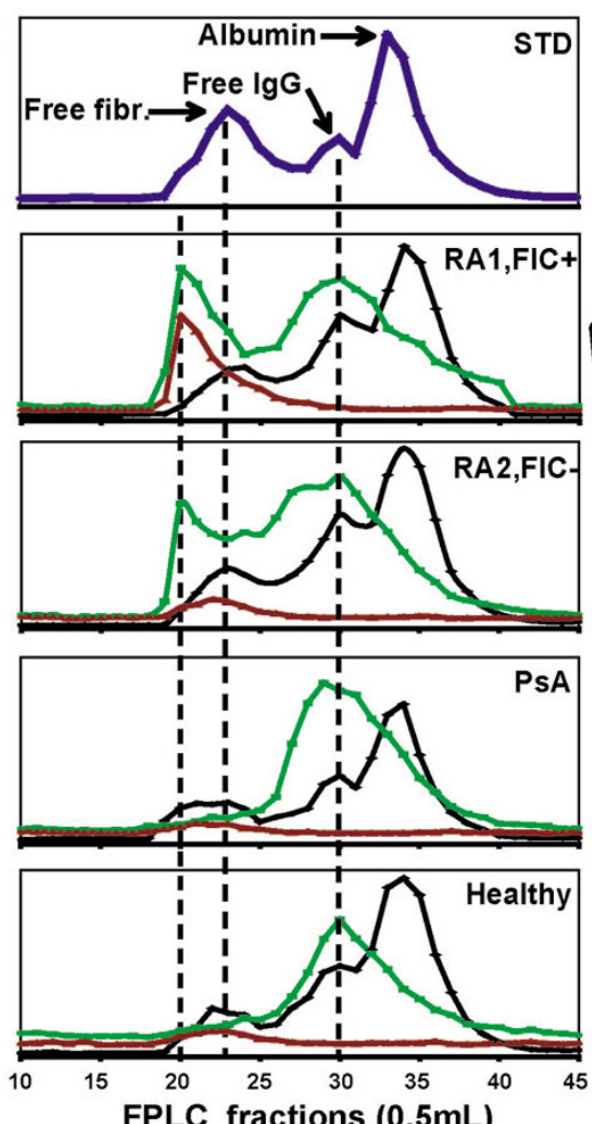

FPLC fractions $(0.5 \mathrm{~mL})$

\section{- Total protein \\ - IgG IC \\ - Fibr. IC}

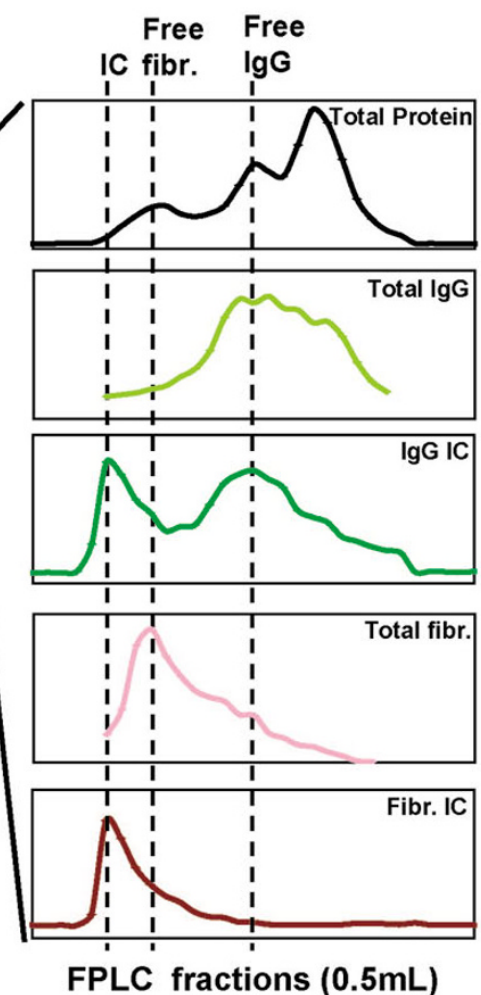

Total IgG

Total fibr.

(b)

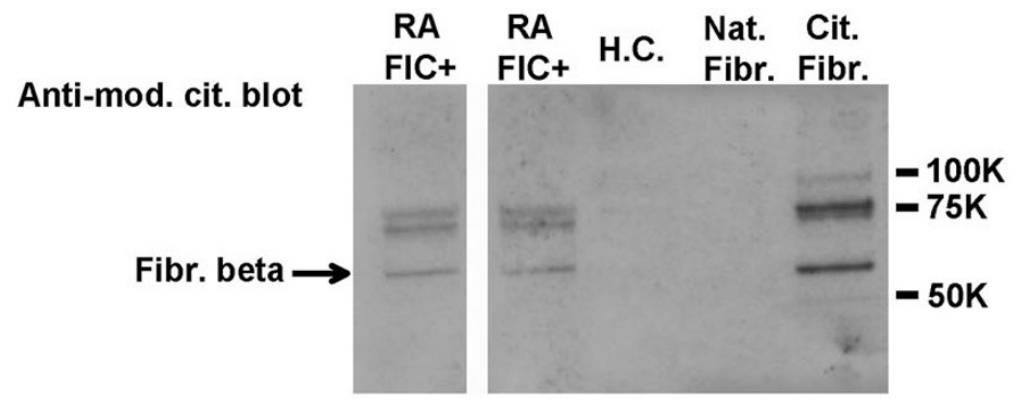

(c)

\begin{tabular}{ccc}
\hline \multicolumn{3}{l}{ Peptide hits of fibrinogen beta chain by mass spectrometry } \\
\hline Residue number & Peptide Sequence & lons score \\
\hline $54-72$ & EEAPSL(cit)PAPPPISGGGYRA & 46 \\
$248-267$ & GGETSEMYLIQPDSSVKPY(cit) & 88 \\
\hline
\end{tabular}

Citrullinated fibrinogen-containing immune complexes (ICs) are separated from rheumatoid arthritis (RA) plasma. (a) Liquid chromatographic separation of RA plasma. Fast protein liquid chromatography (FPLC) was used to fractionate plasma derived from RA and control patients. Forty-five fractions were collected from each plasma sample, and individual fractions were analysed for total protein, fibrinogen, IgG, IgG ICs and fibrinogen ICs (FIC), and relative levels of each of these components are plotted. Plasma samples from two RA patients (RA1 and RA2), a psoriatic arthritis (PsA) patients and a healthy control were characterised. The right panel presents individual traces from patient RA1, with the dashed lines indicating the fractions containing the peak levels of ICs, free fibrinogen and free Ig. (b) Citrullinated fibrinogen was identified by anti-modified citrulline blot. (c) Ingel trypsin digestion of the bands followed by mass spectrometry revealed two citrullinated peptides derived from beta chain of human fibrinogen. 
(a)

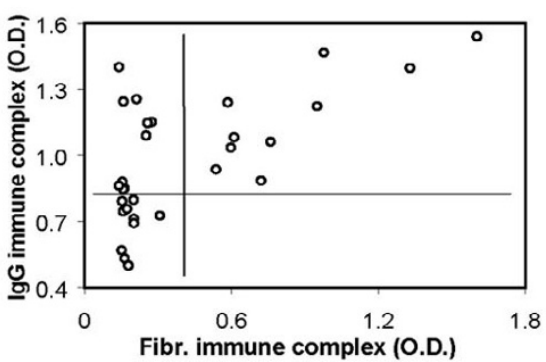

(c)

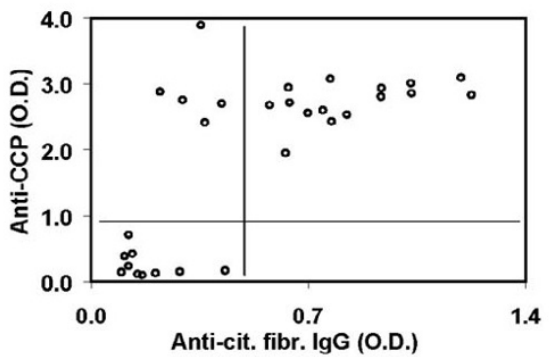

(e)

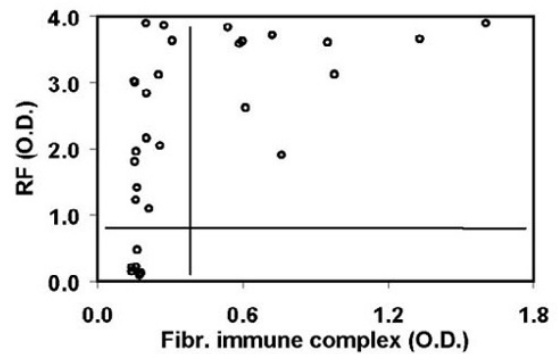

(g)

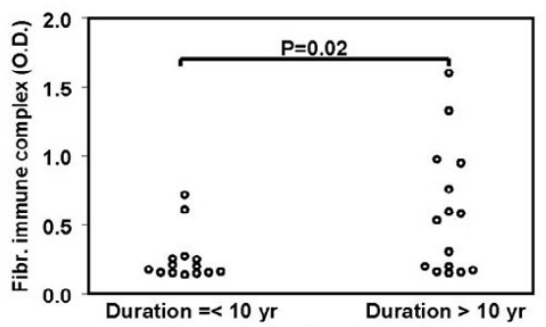

Disease duration (years) (b)

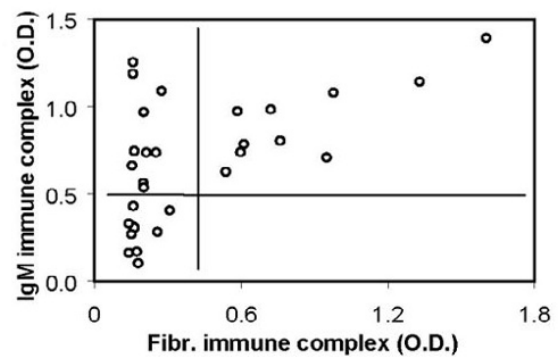

(d)

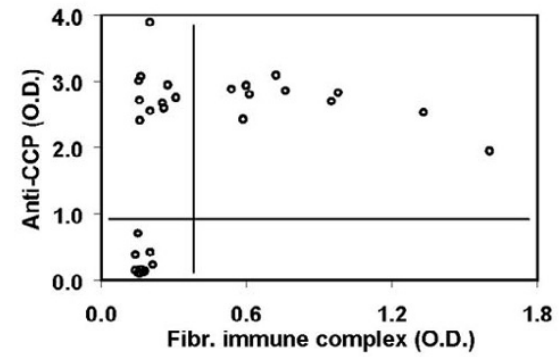

(f)

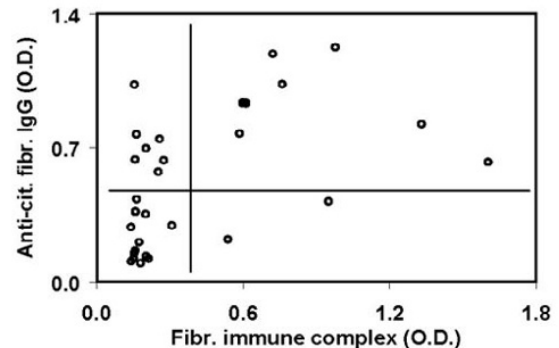

(h)

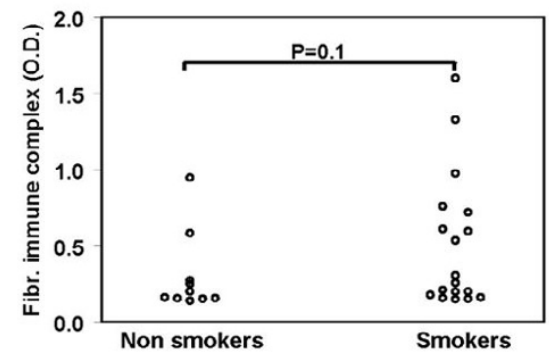

(i)

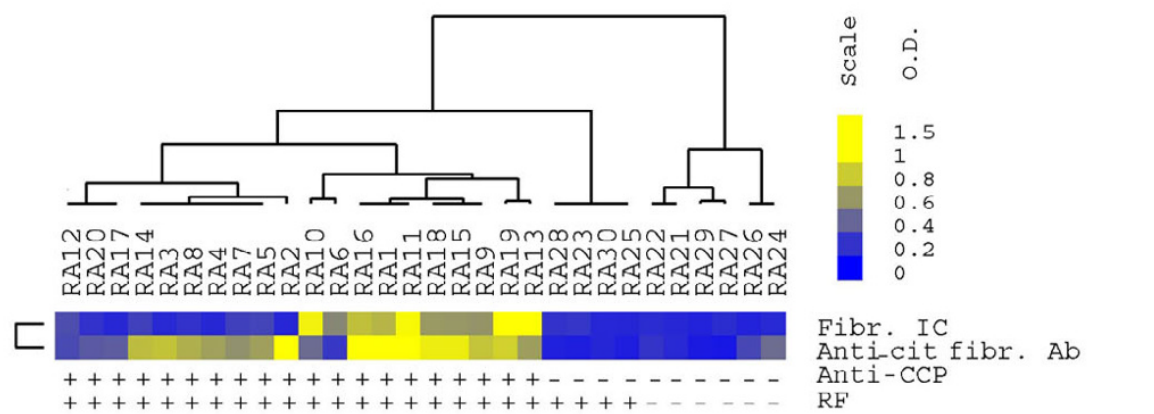

Fibrinogen-containing circulating immune complexes (ICs) are associated with anti-cyclic-citrullinated peptides (CCP) antibodies, rheumatoid factor (RF) and a disease duration of more than 10 years. Scatter plots are presented for the association of (a, b) fibrinogen ICs with IgG and IgM ICs; (c) anti-citrullinated fibrinogen antibodies with anti-CCP antibodies; (d) fibrinogen ICs with anti-CCP antibodies; (e) RF; and (f) anti-citrullinated fibrinogen. Lines were drawn to mark the negative and positive measurements of each species. $(\mathbf{g}, \mathbf{h})$ Levels of fibrinogen ICs are also plotted in RA patients with (g) more than 10 years disease duration and (h) smoking history. (i) Unsupervised hierarctical clustering [54] of 30 RA patients and levels of fibrinogen-circulating ICs, anti-citrullinated fibrinogen antibodies, RF and anti-CCP are presented as a heatmap. Tree dendrograms represent the statistical relatedness between patients. 
3e, i). Interestingly, fibrinogen-containing ICs were not detected in a subset of the RA patients who possessed high IgG and IgM plasma ICs, suggesting that circulating ICs containing other antigens are present in this subset of RA patients (Figures $3 a, b$ ). In RA patients, the presence of circulating ICs containing fibrinogen was associated with a disease duration of more than 10 years $(p=0.02$; Figure $3 g$ ), and there were trends towards associations with smoking $(p=0.1$; Figure 3h).

Unsupervised hierarchical clustering of 30 RA patients based on their anti-CCP antibody, RF, anti-citrullinated fibrinogen antibody and fibrinogen-containing circulating IC levels demonstrates statistical groupings (Figure $3 \mathrm{i}$ ). The anti-CCP+ RF+ patients cluster together, and more than one-half of these patients possess anti-citrullinated fibrinogen autoantibodies and circulating ICs containing fibrinogen.

\section{Immunohistochemistry demonstrates co-staining of fibrinogen, complement component $\mathrm{C}_{3}$, and immunoglobulin in pannus tissue derived from RA patients}

To further investigate the role of fibrinogen-containing ICs in $\mathrm{RA}$, we performed immunohistochemistry on remnant pannus tissue derived from two anti-CCP+ RF+ RA patients. Pannus tissue was obtained from RA patients at the time of knee arthroplasty, fixed and sectioned, then consecutive sections were stained with antibodies specific for complement component C3, fibrinogen and immunoglobulin. Representative results are presented from the analysis of consecutive sections of pannus derived from two independent patients. Immunohistochemical staining demonstrates co-localisation of the complement component $\mathrm{C} 3$, fibrinogen, and $\operatorname{lgG}$ in both RA patients (Figures 4a,b).

RA synovial tissue was minced and the protein contents extracted with tissue protein extraction buffer. Lysates were immunoprecipitated with protein-G-sepharose to capture ICs present in the rheumatoid synovial tissue. These ICs were eluted from the protein-G beads, trypsinised and the trypsin digests directly analysed by mass spectroscopy to demonstrate the presence of citrullinated fibrinogen in ICs isolated from RA pannus tissue (Figure 4c). These data suggest that citrullinated-fibrinogen containing ICs either deposit or form in synovial tissue in RA. The co-localisation of citrullinated fibrinogen-containing ICs with complement component $\mathrm{C} 3$ in RA pannus further suggests that they could activate the complement cascade to cause synovitis in RA.

\section{Discussion}

The presence of ICs in the blood and inflamed joints of patients with RA was described decades ago [30], and several recent findings have resulted in a resurgence of interest in the role of autoantibodies and B cells in RA. These findings include the facts that: anti-citrullinated protein autoantibodies can predate the development of clinical arthritis and provide a sensitivity of approximately $70 \%$ and a specificity of $97 \%$ for the diagnosis of RA [7,11,12,31]; anti-CD20-mediated B cell depletion provides efficacy in treating RA [9]; and the K/BxN mouse model develops spontaneous arthritis mediated by antibodies targeting the ubiquitous glycolytic enzyme GPI [32]. Although ICs have been isolated from RA patient plasma by means of polyethylene glycol precipitation [33] and C1q affinity columns [22], the identity of the antigens incorporated in these ICs is not well defined. In the present study we characterise circulating and synovial tissue ICs, and demonstrate the presence of circulating ICs containing fibrinogen in onehalf of anti-CCP+ RA patients (Figure 1). We used immunoblotting and mass spectroscopy to demonstrate that the fibrinogen contained in these circulating ICs is citrullinated (Figures $2 \mathrm{~b}, \mathrm{c})$, and that ICs isolated from RA pannus tissue also contain citrullinated fibrinogen (Figure 4c). Finally, we demonstrate co-localisation of complement component C3, fibrinogen and immunoglobulin in RA pannus tissue (Figures $4 a, b)$, suggesting that these complexes contribute to synovitis in RA.

Although it is difficult to completely exclude the possibility that the ICs detected are formed in vivo rather than ex vivo, Figure $1 f$ provides reassurance that freezing and freeze-thaw are not responsible for the observed ICs. Further, fibrinogen-containing ICs were not observed in plasma derived from patients with a variety of other inflammatory arthritidies for which the plasma was collected and stored alongside the anti-CCP+ RA plasma in which fibrinogen ICs were demonstrated (Figures $1 \mathrm{c}, \mathrm{d})$. Although complement containing ICs usually bind to erythrocytes and are transported to the liver for clearance, in plasma derived from anti-CCP+ RA patients we found circulating $\mathrm{C} 1 \mathrm{q}$-bound ICs that contain fibrinogen. Further, fibrinogen ICs were also detected by anti-C1q monoclonal antibody capture and results were concordant with our results from C1q capture of ICs (comparison of results yielded a $\mathrm{R}^{2}$ value of 0.9 in linear regression; data not shown).

There is growing evidence that fibrin could be an important autoantigen in RA $[13,18]$. Consistent with previous findings [34], autoantibody reactivity is only observed against citrullinated fibrinogen, and not against its native form (data not shown). Although the anti-citrullinated fibrinogen antibodies observed in RA do not result in overt clinical haematological manifestations, RA is characterised by extravascular coagulation and the accumulation of fibrin in the arthritic joint $[17,35]$. It has been hypothesised that a local imbalance between coagulation and fibrinolysis contributes to pathogenesis, and it is possible that autoantibodies targeting citrullinated fibrinogen could contribute to this imbalance by altering the structural and/or functional properties of fibrinogen and/or fibrin.

Fibrin is one of the classical citrulline-modified proteins [36], and the presence of citrullinated fibrinogen and/or fibrin has 
(a)
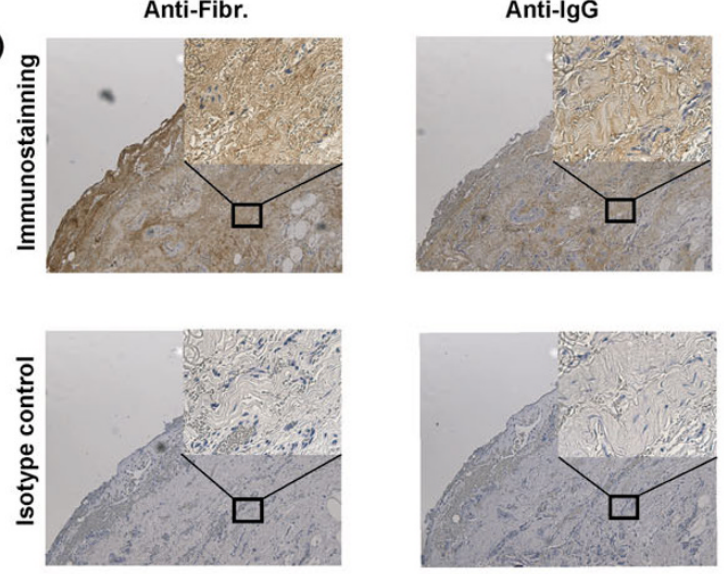

(b)
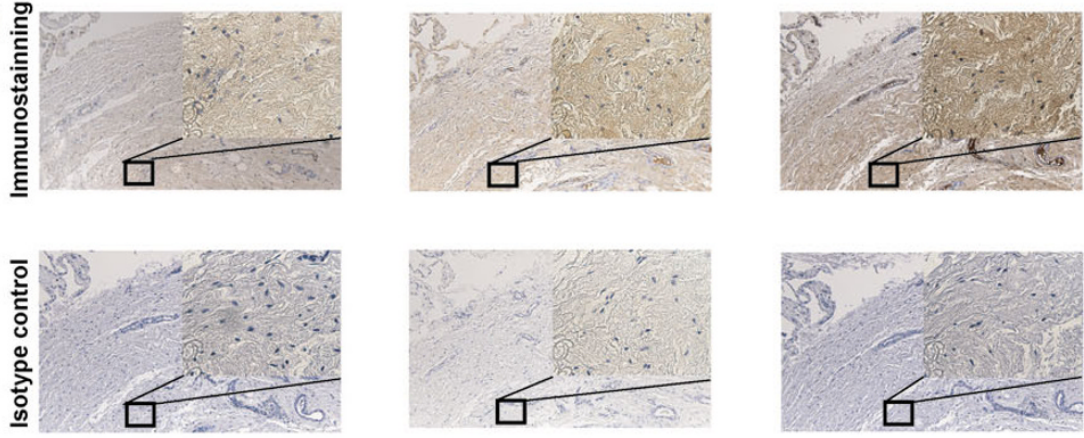

(c)

\begin{tabular}{ccc}
\hline Peptide hits by mass spectrometry & & \\
\hline Residue number & Peptide Sequence & lons score \\
\hline 248-267 (fibrinogen beta chain) & GGETSEMYLIQPDSSVKPY(cit) & 83 \\
$96-108$ (fibrinogen gamma chain) & YEASILTHDSSI(cit) & 57 \\
\hline
\end{tabular}

Synovial tissue immune complexes (ICs) contain citrullinated fibrinogen. (a, b) immunohistochemistry demonstrates co-localisation of fibrinogen, complement component C3 and immunoglobulins in rheumatoid arthritis (RA) pannus tissue. Representative staining of synovium derived from two separate cyclic-citrullinated peptides (CCP) + rheumatoid factor (RF) + RA patients are shown in (a) and (b). Immunohistochemistry was performed on articular cartilage samples derived from RA patients. Samples were fixed, paraffin-embedded and sections stained with antisera specific for complement component $\mathrm{C} 3$, fibrinogen and IgG, as well as with matched pre-immune sera. Horseradish peroxidase (HRP)-conjugated secondary antibodies were utilised to detect primary antibody reactivity. These stainings demonstrate co-localisation of complement component $\mathrm{C} 3$, fibrinogen and immunoglobulin staining at the surface of the articular cartilage sections. (c) Mass spectrometry analysis of ICs immunoprecipitated from RA synovial tissue demonstrates the presence of citrullinated fibrinogen peptides.

been demonstrated in the rheumatoid joint [14,37]. Nevertheless, citrullinated fibrinogen is generated in inflamed synovia arising from a variety of inflammatory conditions [37]. Our observation that ICs containing citrullinated fibrinogen are present in the plasma of anti-CCP+ RA patients, but not in plasma derived from anti-CCP- RA, anti-CCP-juvenile RA and PsA patients (Figures 1 and 2), suggests a potential role for citrullinated fibrinogen-containing circulating ICs in RA. Our mass spectrometry analysis of the fibrinogen contained in circulating ICs derived from anti-CCP+ RA patients demonstrated a few citrullinated peptides from the $\alpha$-chain of fibrinogen, but these peptides were not included in Figure 2c because of low Mascot scores. Our results are consistent with several previous publications that describe citrullinated epitopes derived from the beta, but not the alpha, chain of fibrinogen $[38,39]$. Although trypsin has been described to be incapable of cleaving C-terminal to citrulline residues [40], two of the three citrullinated peptides identified contain a citrulline at the C-terminus (Figures $2 \mathrm{c}$ and $4 \mathrm{c}$ ). Using mass spectrometry analysis, we have detected multiple citrullinated peptides with C-terminal citrullines (as well as non-C terminal citrullines) in tryspin digests of multiple different citrullinated proteins in 
several experiments. In addition, citrullinated peptides with Cterminal citrullines were also observed from multiple citrullinated proteins that were sent to and analysed by an independent mass spectrometry core facility. The explanation for this observation remains unclear, and it is possible that our results are due to altered trypsin cleavage, which is polypeptide sequence and/or trypsin reaction condition dependent. The highly significant Mascot scores of our reported citrullinated peptides (Figures 2c and 4c) support the validity of our results.

The excessive formation of fibrin in the rheumatoid joint in combination with its citrullination and structural properties that include repetitive antigenic motifs, could result in activation of $B$ cells specific for citrullinated fibrinogen via cross-linking of surface immunoglobulin receptors. Citrullination of collagen was demonstrated to increase its immunogenicity and arthritogenicity in a rat arthritis model [41]. Recently, immunisation with citrullinated fibrinogen was described to induce arthritis in human leucocyte antigen (HLA) DR4-IE expressing transgenic mice, demonstrating the arthritogenic potential of citrullinated fibrinogen in mice expression RA-associated major histocompatibility complex (MHC) class II molecules [42].

Fibrin and/or fibrinogen plays an important role in a variety of inflammatory and immunological processes. Multiple cells, including neutrophils and macrophages, express integrins and other receptors that bind fibrin and/or fibrinogen [43]. Fibrinogen has also been hypothesised to serve as a structural scaffold for the formation and growth of pannus [44]. Fibrinogen is chemotactic for endothelial cells that are involved in angiogenesis [45], which is integral to the formation of pannus. Fibrin deposits in RA synovial tissue are hypothesised to activate synovial fibroblast proliferation and cytokine release, as well as other inflammatory cell responses [17]. Fibrinogen has been shown to stimulate macrophage chemokine secretion through TLR-4 [46]. Further, it was recently demonstrated that RA-specific autoantibodies complexed to citrullinated fibrinogen stimulate macrophages to produce TNF via engagement of Fc $\gamma \mathrm{R}$ lla [47].

Cantaert and colleagues suggested that the expression of citrullinated proteins is essential but not sufficient for the development of RA, and that generation of well-defined citrullinated epitopes is likely to play a critical role [48]. In this context, our results might suggest that the development of autoantibodies targeting citrullinated epitopes specific to fibrinogen might play an important role in the pathogenesis of RA. In further support of a potential pathogenic role for citrullinated fibrinogen in RA, it was recently demonstrated that citrullinated fibrinogen bound by autoantibodies present in RA patient sera stimulate macrophage through Fc $\gamma$ Rlla to secrete TNF [47].

It was unexpected to observe autoantibodies targeting citrullinated fibrinogen along with fibrinogen-containing circulating ICs in a subset of juvenile RA patients (Figure 1 and Table 2).
However, late-onset polyarticular juvenile RA is associated with RF-positivity in about $5 \%$ of patients, and has been considered to be identical to adult RA. Further, a recent report described $13 \%$ of polyarticular-onset juvenile RA patients exhibiting anti-CCP antibodies [29]. Following the observation of anti-citrullinated fibrinogen autoatibodies and fibrinogencontaining circulating ICs in a subset of juvenileRA patients (Table 2), we performed chart reviews with anti-CCP and RF ELISA tests on these plasma samples. Of the six juvenile RA patients exhibiting elevated levels of anti-citrullinated fibrinogen antibodies, all exhibited a symmetrical polyarthritis and possessed RF antibodies. All but one of the six anti-CCP+ and $\mathrm{RF}+$ juvenile RA patients possessed high levels of fibrinogen ICs. The age of disease onset of the anti-CCP+ and RF+ juvenile RA patients were $13,11,3,13$ and 9 years, and these patients were relatively older than the other juvenile RA patients included in this cohort. Interestingly, five out of six anti-CCP+ and RF+ juvenile RA patients possessed fibrinogen-containing ICs, compared with only $50 \%$ of anti-CCP+ and RF+ adult RA patients. This observation suggests that anti-fibrinogen autoimmunity and fibrinogen-containing ICs play a significant role in this subset of juvenile RA patients. Characterisation of larger cohorts of juvenile RA patients will be necessary to validate and further investigate this observation.

Immunohistochemical analysis demonstrated co-localisation of the staining for fibrinogen, complement component $\mathrm{C} 3$ and immunoglobulin in serial sections derived from RA pannus tissue (Figure 4). These results suggest that fibrinogen-containing ICs deposit on or form in synovial lining tissue, and activate the complement cascade to cause inflammatory arthritis. In the $\mathrm{K} / \mathrm{BxN}$ model, arthritis is mediated by anti-GPI antibodies and was demonstrated to depend on FcR $\gamma$ and components of the alternative complement pathway [49]. It has been speculated that accumulation of ICs involving GPI may activate the alternative complement pathway to cause inflammatory arthritis [16]. We hypothesise that autoantibodies targeting citrullinated fibrinogen could result in IC-mediated arthritis based on mechanisms analogous to those observed in the $\mathrm{K} / \mathrm{BxN}$ model [16] and via macrophage Fc $\gamma$ Rlla-mediated TNF production [47].

Anti-citrullinated fibrinogen autoantibodies were detected in three-quarters of anti-CCP+ RA patients (data not shown) while fibrinogen containing ICs were found in one-half (Figures 1 and 3). These observations are consistent with RA being a clinically and molecularly heterogeneous disease, as evidenced by differential expression of anti-citrulline antibodies $[7,11]$, variable responsiveness to anti-tumor necrosis factor (TNF) therapy [50] and heterogeneity in the genetic background of patients which includes polymorphisms in the $\mathrm{MHC}$ (major histocompatibility complex), TRAF1-C5 (encoding tumor necrosis factor receptor-associated factor 1 and complement component 5) [51], STAT4 (encoding signal trans- 
ducer and activator of transcription 4) [51,52] and PTPN22 (encoding protein tyrosine phosphatase, non-receptor type 22) [53] genes. CCP is derived from filaggrin, a protein expressed by keratinocytes in the epidermis, and it is likely that autoantibody reactivity against the CCPs derived from filaggrin represents molecular cross reactivity. Our findings suggest that the development of citrullinated fibrinogencontaining ICs in RA synovial tissue activates the complement cascade and contributes to synovitis in RA.

\section{Conclusion}

In summary, the data presented herein suggest that autoimmunity targeting citrullinated fibrinogen and the development of fibrinogen-containing ICs could contribute to synovitis in approximately one-half of anti-CCP+ RA patients. These results expand the possibility for the development of novel diagnostics as well as for the development of specific therapies for this subset of RA patients.

\section{Competing interests}

The authors declare that they have no competing interests.

\section{Authors' contributions}

X.Z. and W.H.R. conceived the studies, carried out the experiments, analyzed the data, and wrote the manuscript. N.L.O. and O.S. helped perform the mass spectrometry experiments. F.M.B., A.T.L. and P.K.G. provided human samples and clinical data, and contributed to interpretation of the data. P.P.H. and B.H.T. contributed to data analysis.

\section{Acknowledgements}

We thank members of the Robinson laboratory and Elizabeth Chlipala (Premier Laboratory) for their scientific input. This work was funded by a T. Franklin Williams Scholars grant, an Arthritis Foundation Investigator Award, NIH NHLBI contract N01 HV 28183, NIH NIAMS R21 Al069160, and Veterans Affairs Health Care System funding to W.H.R. The mass spectrometry work was supported by the Stanford Digestive Disease Center grant NIH P30 DK56339.

\section{References}

1. Firestein GS: Evolving concepts of rheumatoid arthritis. Nature 2003, 423:356-361.

2. Zubler RH, Nydegger U, Perrin LH, Fehr K, McCormick J, Lambert $\mathrm{PH}$, Miescher PA: Circulating and intra-articular immune complexes in patients with rheumatoid arthritis. Correlation of $125 \mathrm{I}-\mathrm{Clq}$ binding activity with clinical and biological features of the disease. J Clin Invest 1976, 57:1308-1319.

3. Antes U, Heinz HP, Schultz D, Brackertz D, Loos M: C1q-bearing immune complexes detected by a monoclonal antibody to human $\mathrm{C} 1 \mathrm{q}$ in rheumatoid arthritis sera and synovial fluids. Rheumatol Int 1991, 10:245-250.

4. Low JM, Moore TL: A role for the complement system in rheumatoid arthritis. Curr Pharm Des 2005, 11:655-670.

5. Newkirk MM, Fournier MJ, Shiroky J: Rheumatoid factor avidity in patients with rheumatoid arthritis: identification of pathogenic RFs which correlate with disease parameters and with the gal(0) glycoform of IgG. J Clin Immunol 1995, 15:250-257.

6. Steffen C, Ludwig H, Knapp W, Thumb N, Eberl R, Frank O, Freilinger $\mathrm{H}$ : Collagen antibodies and collagen-anticollagen immune complexes in rheumatoid arthritis. Z Rheumatol 1975, 34:391-399.
7. Schellekens GA, de Jong BA, Hoogen FH van den, Putte LB van de, van Venrooij WJ: Citrulline is an essential constituent of antigenic determinants recognized by rheumatoid arthritisspecific autoantibodies. J Clin Invest 1998, 101:273-281.

8. Kuhn KA, Kulik L, Tomooka B, Braschler KJ, Arend WP, Robinson $\mathrm{WH}$, Holers VM: Antibodies against citrullinated proteins enhance tissue injury in experimental autoimmune arthritis. $J$ Clin Invest 2006, 116:961-973.

9. Edwards JC, Szczepanski L, Szechinski J, Filipowicz-Sosnowska A, Emery P, Close DR, Stevens RM, Shaw T: Efficacy of B-celltargeted therapy with rituximab in patients with rheumatoid arthritis. N Engl J Med 2004, 350:2572-2581.

10. Agrawal S, Misra R, Aggarwal A: Autoantibodies in rheumatoid arthritis: association with severity of disease in established RA. Clin Rheumato/ 2007, 26:201-204.

11. Schellekens GA, Visser $H$, de Jong BA, Hoogen $F H$ van den, Hazes JM, Breedveld FC, van Venrooij WJ: The diagnostic properties of rheumatoid arthritis antibodies recognizing a cyclic citrullinated peptide. Arthritis Rheum 2000, 43:155-163.

12. Mimori T: Clinical significance of anti-CCP antibodies in rheumatoid arthritis. Intern Med 2005, 44:1122-1126.

13. Masson-Bessiere C, Sebbag M, Girbal-Neuhauser E, Nogueira L, Vincent C, Senshu T, Serre G: The major synovial targets of the rheumatoid arthritis-specific antifilaggrin autoantibodies are deiminated forms of the alpha- and beta-chains of fibrin. $J$ Immunol 2001, 166:4177-4184

14. Takizawa $Y$, Suzuki A, Sawada T, Ohsaka M, Inoue T, Yamada R, Yamamoto K: Citrullinated fibrinogen detected as a soluble citrullinated autoantigen in rheumatoid arthritis synovial fluids. Ann Rheum Dis 2006, 65:1013-1020.

15. Korganow AS, Ji H, Mangialaio S, Duchatelle V, Pelanda R, Martin T, Degott C, Kikutani H, Rajewsky K, Pasquali JL, Benoist C, Mathis $D$ : From systemic $T$ cell self-reactivity to organ-specific autoimmune disease via immunoglobulins. Immunity 1999, 10:451-461.

16. Matsumoto I, Maccioni M, Lee DM, Maurice M, Simmons B, Brenner $M$, Mathis $D$, Benoist $C$ : How antibodies to a ubiquitous cytoplasmic enzyme may provoke joint-specific autoimmune disease. Nat Immunol 2002, 3:360-365.

17. Sanchez-Pernaute $O$, Largo R, Calvo E, Alvarez-Soria MA, Egido J, Herrero-Beaumont G: A fibrin based model for rheumatoid synovitis. Ann Rheum Dis 2003, 62:1135-1138.

18. Cruyssen $B$ Vander, Cantaert $T$, Nogueira L, Clavel C, De Rycke L, Dendoven A, Sebag M, Deforce D, Vincent C, Elewaut D, Serre G, De Keyser F: Diagnostic value of anti-human citrullinated fibrinogen ELISA and comparison with four other anti-citrullinated protein assays. Arthritis Res Ther 2006, 8:R122.

19. Nielen MM, Horst AR van der, van Schaardenburg D, Horst-Bruinsma IE van der, Stadt RJ van de, Aarden L, Dijkmans BA, Hamann $D$ : Antibodies to citrullinated human fibrinogen (ACF) have diagnostic and prognostic value in early arthritis. Ann Rheum Dis 2005, 64:1199-1204.

20. Hueber W, Kidd BA, Tomooka BH, Lee BJ, Bruce B, Fries JF, Sønderstrup G, Monach P, Driifhout JW, van Venrooij WJ, Utz PJ, Genovese MC, Robinson WH: Antigen microarray profiling of autoantibodies in rheumatoid arthritis. Arthritis Rheum 2005, 52:2645-2655.

21. Kunkel HG, Muller-Eberhard HJ, Fudenberg HH, Tomasi TB: Gamma globulin complexes in rheumatoid arthritis and certain other conditions. J Clin Invest 1961, 40:117-129.

22. Khalkhali-Ellis Z, Bulla GA, Schlesinger LS, Kirschmann DA, Moore $\mathrm{TL}$, Hendrix MJ: C1q-containing immune complexes purified from sera of juvenile rheumatoid arthritis patients mediate IL8 production by human synoviocytes: role of $\mathrm{C} 1 \mathrm{q}$ receptors. $J$ Immunol 1999, 163:4612-4620.

23. Criswell LA, Pfeiffer KA, Lum RF, Gonzales B, Novitzke J, Kern M, Moser KL, Begovich AB, Carlton VE, Li W, Lee AT, Ortmann W, Behrens TW, Gregersen PK: Analysis of families in the multiple autoimmune disease genetics consortium (MADGC) collection: the PTPN22 620W allele associates with multiple autoimmune phenotypes. Am J Hum Genet 2005, 76:561-571.

24. Arnett FC, Edworthy SM, Bloch DA, McShane DJ, Fries JF, Cooper NS, Healey LA, Kaplan SR, Liang MH, Luthra HS, Medsger TA, Mitchell DM, Neustadt DH, Pinals RS, Schaller JG, Sharp JT, Wilder RL, Hunder GG: The American Rheumatism Association 1987 revised criteria for the classification of rheumatoid arthritis. Arthritis Rheum 1988, 31:315-324. 
25. Vossenaar ER, Despres N, Lapointe E, Heijden A van der, Lora M, Senshu T, van Venrooij WJ, Menard HA: Rheumatoid arthritis specific anti-Sa antibodies target citrullinated vimentin. Arthritis Res Ther 2004, 6:R142-150.

26. Chapuy-Regaud S, Nogueira L, Clavel C, Sebbag M, Vincent C, Serre G: IgG subclass distribution of the rheumatoid arthritisspecific autoantibodies to citrullinated fibrin. Clin Exp Immunol 2005, 139:542-550.

27. Senshu $T$, Akiyama $K$, Kan $S$, Asaga $H$, Ishigami $A$, Manabe $M$ : Detection of deiminated proteins in rat skin: probing with a monospecific antibody after modification of citrulline residues. $J$ Invest Dermatol 1995, 105:163-169.

28. Agnello V, Winchester RJ, Kunkel HG: Precipitin reactions of the C1q component of complement with aggregated gammaglobulin and immune complexes in gel diffusion. Immunology 1970, 19:909-919.

29. Ferucci ED, Majka DS, Parrish LA, Moroldo MB, Ryan M, Passo M, Thompson SD, Deane KD, Rewers M, Arend WP, Glass DN, Norris JM, Holers VM: Antibodies against cyclic citrullinated peptide are associated with HLA-DR4 in simplex and multiplex polyarticular-onset juvenile rheumatoid arthritis. Arthritis Rheum 2005, 52:239-246.

30. Zvaifler NJ: The immunopathology of joint inflammation in rheumatoid arthritis. Adv Immunol 1973, 16:265-336.

31. Nielen MM, van Schaardenburg D, Reesink HW, Stadt RJ van de, Horst-Bruinsma IE van der, de Koning MH, Habibuw MR, Vandenbroucke JP, Dijkmans BA: Specific autoantibodies precede the symptoms of rheumatoid arthritis: a study of serial measurements in blood donors. Arthritis Rheum 2004, 50:380-386.

32. Matsumoto I, Staub A, Benoist C, Mathis D: Arthritis provoked by linked $T$ and $B$ cell recognition of a glycolytic enzyme. Science 1999, 286:1732-1735.

33. Ferraccioli G, Karsh J, Osterland CK: Immunochemical analyses of components of immune complexes in the sera of patients with autoimmune diseases. J Rheumatol 1983, 10:881-888.

34. Hill JA, Al-Bishri J, Gladman DD, Cairns E, Bell DA: Serum autoantibodies that bind citrullinated fibrinogen are frequently found in patients with rheumatoid arthritis. J Rheumatol 2006, 33:2115-2119.

35. Busso N, Hamilton JA: Extravascular coagulation and the plasminogen activator/plasmin system in rheumatoid arthritis. Arthritis Rheum 2002, 46:2268-2279.

36. Vossenaar ER, Zendman AJ, van Venrooij WJ, Pruijn GJ: PAD, a growing family of citrullinating enzymes: genes, features and involvement in disease. Bioessays 2003, 25:1106-1118.

37. Chapuy-Regaud S, Sebbag M, Baeten D, Clavel C, Foulquier C, De Keyser F, Serre G: Fibrin deimination in synovial tissue is not specific for rheumatoid arthritis but commonly occurs during synovitides. J Immunol 2005, 174:5057-5064.

38. Tilleman K, Van Steendam K, Cantaert T, De Keyser F, Elewaut D, Deforce D: Synovial detection and autoantibody reactivity of processed citrullinated isoforms of vimentin in inflammatory arthritides. Rheumatology (Oxford) 2008, 47:597-604.

39. Matsuo $\mathrm{K}$, Xiang $\mathrm{Y}$, Nakamura $\mathrm{H}$, Masuko $\mathrm{K}$, Yudoh $\mathrm{K}$, Noyori $\mathrm{K}$ Nishioka K, Saito T, Kato T: Identification of novel citrullinated autoantigens of synovium in rheumatoid arthritis using a proteomic approach. Arthritis Res Ther 2006, 8:R175.

40. Kurokawa T, Hara S, Takahara H, Sugawara K, Ikenaka T: Conversion of peanut trypsin-chymotrypsin inhibitor B-III to a chymotrypsin inhibitor by deimination of the $\mathrm{P} 1$ arginine residues in two reactive sites. J Biochem 1987, 101:1361-1367.

41. Lundberg K, Nijenhuis S, Vossenaar ER, Palmblad K, van Venrooij WJ, Klareskog L, Zendman AJ, Harris HE: Citrullinated proteins have increased immunogenicity and arthritogenicity and their presence in arthritic joints correlates with disease severity. Arthritis Res Ther 2005, 7:R458-467.

42. Hill JA, Bell DA, Brintnell W, Yue D, Wehrli B, Jevnikar AM, Lee DM, Hueber W, Robinson WH, Cairns E: Arthritis induced by posttranslationally modified (citrullinated) fibrinogen in DR4IE transgenic mice. J Exp Med 2008, 205:967-979.

43. Wright SD, Weitz JI, Huang AJ, Levin SM, Silverstein SC, Loike JD: Complement receptor type three (CD11b/CD18) of human polymorphonuclear leukocytes recognizes fibrinogen. Proc Natl Acad Sci USA 1988, 85:7734-7738.

44. Ishikawa $\mathrm{H}$, Hirata $\mathrm{S}$, Andoh $\mathrm{Y}, \mathrm{Kubo} \mathrm{H}$, Nakagawa N, Nishibayashi $Y$, Mizuno K: An immunohistochemical and immunoelectron microscopic study of adhesion molecules in synovial pannus formation in rheumatoid arthritis. Rheumatol Int 1996, 16:53-60.

45. Dejana E, Languino LR, Polentarutti N, Balconi G, Ryckewaert JJ, Larrieu MJ, Donati MB, Mantovani A, Marguerie G: Interaction between fibrinogen and cultured endothelial cells. Induction of migration and specific binding. $J$ Clin Invest 1985, 75:11-18.

46. Smiley ST, King JA, Hancock WW: Fibrinogen stimulates macrophage chemokine secretion through toll-like receptor 4 . J Immunol 2001, 167:2887-2894

47. Clavel C, Nogueira L, Laurent L, lobagiu C, Vincent C, Sebbag M, Serre G: Induction of macrophage secretion of tumor necrosis factor alpha through Fcgamma receptor Ila engagement by rheumatoid arthritis-specific autoantibodies to citrullinated proteins complexed with fibrinogen. Arthritis Rheum 2008, 58:678-688

48. Cantaert T, De Rycke L, Bongartz T, Matteson EL, Tak PP, Nicholas AP, Baeten D: Citrullinated proteins in rheumatoid arthritis: crucial but not sufficient! Arthritis Rheum 2006, 54:3381-3389.

49. Ji H, Gauguier D, Ohmura K, Gonzalez A, Duchatelle V, Danoy P, Garchon HJ, Degott C, Lathrop M, Benoist C, Mathis D: Genetic influences on the end-stage effector phase of arthritis. J Exp Med 2001, 194:321-330.

50. Moreland LW, Schiff MH, Baumgartner SW, Tindall EA, Fleischmann RM, Bulpitt KJ, Weaver AL, Keystone EC, Furst DE Mease PJ, Ruderman EM, Horwitz DA, Arkfeld DG, Garrison L, Burge DJ, Blosch CM, Lange ML, McDonnell ND, Weinblatt ME: Etanercept therapy in rheumatoid arthritis. A randomized, controlled trial. Ann Intern Med 1999, 130:478-486.

51. Plenge RM, Seielstad M, Padyukov L, Lee AT, Remmers EF, Ding B, Liew A, Khalili H, Chandrasekaran A, Davies LR, Li W, Tan AK, Bonnard C, Ong RT, Thalamuthu A, Pettersson S, Liu C, Tian C, Chen WV, Carulli JP, Beckman EM, Altshuler D, Alfredsson L, Criswell LA, Amos Cl, Seldin MF, Kastner DL, Klareskog L, Gregersen PK: TRAF1-C5 as a risk locus for rheumatoid arthritis - a genomewide study. N Engl J Med 2007, 357:1199-1209.

52. Remmers EF, Plenge RM, Lee AT, Graham RR, Hom G, Behrens TW, de Bakker PI, Le JM, Lee HS, Batliwalla F, Li W, Masters SL, Booty MG, Carulli JP, Padyukov L, Alfredsson L, Klareskog L, Chen WV, Amos Cl, Criswell LA, Seldin MF, Kastner DL, Gregersen PK: STAT4 and the risk of rheumatoid arthritis and systemic lupus erythematosus. N Engl J Med 2007, 357:977-986.

53. Begovich AB, Carlton VE, Honigberg LA, Schrodi SJ, Chokkalingam AP, Alexander HC, Ardlie KG, Huang O, Smith AM, Spoerke JM, Conn MT, Chang M, Chang SY, Saiki RK, Catanese JJ, Leong DU, Garcia VE, McAllister LB, Jeffery DA, Lee AT, Batliwalla F, Remmers E, Criswell LA, Seldin MF, Kastner DL, Amos Cl, Sninsky $\mathrm{JJ}$, Gregersen PK: A missense single-nucleotide polymorphism in a gene encoding a protein tyrosine phosphatase (PTPN22) is associated with rheumatoid arthritis. Am J Hum Genet 2004, 75:330-337.

54. Eisen MB, Spellman PT, Brown PO, Botstein D: Cluster analysis and display of genome-wide expression patterns. Proc Nat Acad Sci USA 1998, 95:14863-14868. 